\title{
Oxidative Decolorization of Azo Dye Fast red e by Sodium N- halobenzenesulfonamides in Acid Medium: Kinetic, Mechanistic and Spectrophotometric Study
}

\author{
J.P. Shubha ${ }^{1 *} \cdot$ K. Vinutha ${ }^{1}$, Puttaswamy ${ }^{2}$, K. Gurushantha ${ }^{3}$ \\ ${ }^{I}$ Department of Chemistry, Don Bosco Institute of Technology, Kumbalagodu, Mysore Road Bangalore -560 \\ 074, Karnataka, India \\ ${ }^{2}$ Department of Chemistry, Central College Campus, Bangalore University, Bangalore 560 001, Karnataka, \\ India \\ ${ }^{3}$ Department of Chemistry, East West Institute of Technology, Off Magadi Road, Bangalore - 560 091,
} Karnataka, India

\begin{abstract}
The kinetics of oxidative decolorization of fast red e (FRE) by chloramine-B and bromamine-B in $\mathrm{HClO}_{4}$ medium has been investigated spectrophotometrically $\left(\lambda_{\max }=508 \mathrm{~nm}\right)$ at $298 \mathrm{~K}$. Kinetic runs were performed under pseudo first-order conditions of [oxidant $]_{o} \gg[F R E]_{o}$. Under identical experimental conditions, reactions with both the oxidants follow identical kinetics with a first-order dependence on each [oxidant $]_{o}$ and [FRE] and a fractional-order dependence on $\left[\mathrm{HClO}_{4}\right]$. Stoichiometry of the reaction was found to be 1:1 and the oxidation products were identified. The reaction was studied at different temperatures and various activation parameters have been computed. Effects of p-toluenesulfonamide, halide ions, ionic strength and dielectric constant of the medium have been investigated. Reaction mixture fails to induce polymerization of acrylonitrile. The rate of oxidation of FRE is about three-fold faster with BAB as compared to CAB. This may be attributed to the difference in electrophilicities of $\mathrm{Cl}^{+}$and $\mathrm{Br}^{+}$ions and also the van der Waal's radii of chlorine and bromine. Plausible mechanism and related rate law have been deliberated for the observed kinetics.
\end{abstract}

Key words: Azo dye, Fast red e, Chloramine-B, Bromamine-B, Oxidation-Kinetics, Acid medium

\section{Introduction}

Variety of dyes used in textile industry usually have a synthetic origin and multifaceted aromatic molecular structures which make them more stable and more complicated to be biodegraded [1-3]. Colored industrial effluent is the most apparent indicator of water pollution and the discharge of highly colored synthetic dye effluents is aesthetically displeasing and cause considerable damage to the aquatic life. The effluents are strongly colored which not only created environmental and aesthetic problems, but also posed a great potential toxic threat to ecological human health as most of these dyes are toxic and carcinogenic. Predominantly azo dyes which contain one or more nitrogen to nitrogen double bonds $(-\mathrm{N}=\mathrm{N}-)$ constitutes a significant portion that are widely used in industries today. The strong electron-withdrawing character of the azo group stabilizes these aromatic pollutants against conversions by oxygenases. Therefore, azo dyes are not readily degraded under aerobic conditions. Hence, removal of azo dye effluents generated by food and dye industries is a main issue in waste water treatment. These effluents are commonly treated using physico-chemical methods such as adsorption, photo degradation and coagulation. All of these processes are expensive and complicated. Therefore, there is a need for economical and simple methods to abolish harmful dyes in effluents [1-9].

Fast red e (FRE) is chemically known as disodium-2-hydroxy-1-(4-sulfonato-1-naphthylazo)-6naphthalenesulfonate and is used in food stuffs [1]. An extensive literature survey reveals that there are no reports on the oxidation of FRE by any oxidants from the standpoint of the kinetic and mechanistic approach. Hence, it was felt advisable to investigate the oxidative decolorization of FRE with N-haloamines to explore the kinetic and mechanistic aspects of its redox chemistry.

The most important aim of this work was to promote the decolorization of FRE by N-haloamine, has a low energy cost and is economical. The effectiveness of the proposed process was evaluated by its capability to promote decreases in color and total organic carbon content. The high efficiency observed with the dye model showed that this economic, easily operated and maintained treatment process could also be employed in the remediation of effluents.

The chemistry of a class of N-metallo-N-haloarylsulfonamides, known as N-haloamines, attracted the attention of many investigators due to their diverse behaviour. Their versatile nature is attributed to their ability to act both as bases and nucleophiles [10]. As a result of this, these compounds interact with a wide range of functional groups in aqueous, partially aqueous and non-aqueous media in presence of acids or alkalis, bringing about an array of molecular transformations. In general monohaloamines undergo two electron change while 
dihaloamines act as four electron oxidants. The reduction products obtained are the respective sulfonamide and sodium chloride [11]. The dominant members of this class of chlorocompounds are chloramine-T (CAT) and chloramine-B $(\mathrm{CAB})$. A review of literature reveals that although the reaction of aromatic sulfonyl chloramines have been known and extensively investigated [10, 12-16] there is not much of information [17-20] available on the reaction of corresponding bromamines, bromamine-T and bromamine-B. Sodium Nbromobenzenesulfonamide or bromamine- $\mathrm{B}(\mathrm{BAB})$ has gained importance as a mild oxidant and it can be readily prepared by brominating $\mathrm{CAB}$. Bromamine- $\mathrm{B}$ is found to be a most potential oxidant among these $\mathrm{N}$ haloamines. There are but a few reports [21-22] on the kinetics of oxidation of organic substrates by BAB as compared to the studies with other haloamines as oxidants from mechanistic view point. For these reasons, it was felt interesting to investigate the mechanism of oxidation of FRE with this reagent.

In the light of existing information and in continuation of our research interest on the kinetic and mechanistic investigations of oxidation of various substrates in general and dyes in particular by $\mathrm{CAB}$ and $\mathrm{BAB}$, the title reaction was undertaken. Accordingly, in this communication we report on the comprehensive kinetics of FRE oxidation by $\mathrm{CAB}$ and $\mathrm{BAB}$ in $\mathrm{HClO}_{4}$ medium at $298 \mathrm{~K}$.

\subsection{Materials}

\section{Experimental}

Bromamine-B was prepared [23] by the partial debromination of dibromamine-B (DBB) as follows. Pure chlorine was bubbled through an aqueous solution of chloramine-B (30 g in $560 \mathrm{~mL}$ water) and liquid bromine $(6 \mathrm{~mL})$ was added dropwise with constant stirring. A yellow precipitate of DBB formed was washed well with $\mathrm{H}_{2} \mathrm{O}$, filtered under suction, and dried in a vacuum desiccator. Dibromamine-B (31.5 g) was digested in batches with constant stirring in $50 \mathrm{~mL}$ of $4 \mathrm{~mol} \mathrm{dm}^{-3} \mathrm{NaOH}$. The resulting mass was cooled in ice, filtered under suction, and the product (BAB) was dried over anhydrous calcium chloride. The purity of BAB was tested iodometrically through its active bromine content and its FT-IR spectrum. Aqueous solutions of BAB were prepared, standardized whenever required by the iodometric method and preserved in brown bottles to prevent its photochemical deterioration [24]

Chloramine-B (E. Merck) and fast red e (SDFCL) were used as received. Solvent isotope studies were made with $\mathrm{D}_{2} \mathrm{O}(99.4 \%)$ supplied by BARC, Mumbai, India. Analytical grade chemicals and double distilled water was used throughout.

\subsection{Kinetic measurements}

Kinetic measurements were carried out using a UV-Visible spectrophotometer (Elico SL159). In the present study, the kinetic experiments were carried out between 288 and $308 \mathrm{~K}$. For this purpose, a Raagaa Ultra Cold Chamber with digital temperature control (Chennai, India) was used. The temperature was maintained constant with an accuracy of $\pm 0.1^{0} \mathrm{C}$. Detailed kinetic runs were performed under pseudo first-order conditions of $[\text { oxidant }]_{0} \gg>[\mathrm{FRE}]_{0}$ at $298 \mathrm{~K}$. Reactions were conceded in glass stoppard pyrex boiling tubes whose outer surfaces were coated black to prevent photochemical effects. The oxidant as well as the requisite amounts of FRE, $\mathrm{HClO}_{4}$ solutions and water (to keep the total volume constant for all runs) taken in separate tubes were thermostatted for $30 \mathrm{~min}$ at $298 \mathrm{~K}$. The reaction was initiated by the rapid addition of a measured amount of oxidant to the stirred reaction mixture. Instantaneously, $4 \mathrm{~cm}^{3}$ of the solution was pipetted into a cuvette placed in the UV-Vis spectrophotometer and absorbance measurements were made at $508 \mathrm{~nm}$ ( $\lambda_{\max }$ for FRE) for more than two half-lives. The absorbance readings at $t=0$ and $t=t$ are $D_{0}$ and $D_{t}$. Plots of $\log D_{0} / D_{t}$ versus time were made to evaluate the pseudo first-order rate constants $\left(\mathrm{k}^{\prime}\right)$ which were found reproducible within $\pm 4-5 \%$.

\subsection{Reaction stoichiometry}

Reaction mixtures containing different ratios of oxidant to FRE in presence of $2.0 \times 10^{-3} \mathrm{~mol} \mathrm{dm}^{-3}$ $\mathrm{HClO}_{4}$ were equilibrated at $298 \mathrm{~K}$ for $24 \mathrm{~h}$. The unreacted oxidant in the reaction mixture was determined by iodometric titration. This analysis showed that in both the cases one mole of FRE consumed one mole of oxidant and the observed reaction stoichiometry is represented as: 
<smiles>Cc1ccc(S(=O)(=O)N(N)Cl)cc1</smiles><smiles>C[C+]1C=CC(=O)C(=O)c2ccccc21</smiles>

\subsection{Product analysis}

In the stoichiometric proportion, the reaction mixtures containing different concentrations of oxidant and substrate in $2.0 \times 10^{-3} \mathrm{~mol} \mathrm{dm}^{-4} \mathrm{HClO}_{4}$ under stirred condition was allowed to react for $24 \mathrm{~h}$ at $298 \mathrm{~K}$. After completion of the reaction (monitored by thin layer chromatography), the reaction products were neutralized with alkali and extracted with ether. The organic products were subjected to spot tests and chromatographic analysis, which revealed the formation of naphthalene and naphthaquinone as the oxidation products of FRE and benzenesulfonamide as the reduction product of the oxidant. The products were confirmed by Mass spectral analysis [Fig. $1 \&$ Fig. 2].

The reduction product of the oxidant, benzenesulfonamide, was extracted with ethylacetate and detected by TLC using petroleum ether: $\mathrm{CHCl}_{3}$ : 1-butanol $(2: 2: 1, v / v)$ as the solvent system and iodine as spraying agent $\left(R_{\mathrm{f}}=0.88\right)$. It was further confirmed by GC-MS analysis. Molecular ion peak of $157 \mathrm{amu}$ clearly confirms benzenesulfonamide (Fig. 3). All other peaks observed in MS can be interpreted in accordance with the observed structure. It was also noticed that there was no future oxidation of these products under present kinetic conditions.

\subsection{Effect of reactant concentration on the rate}

\section{Results And Discussion}

The kinetics of oxidation of FRE by $\mathrm{CAB}$ and $\mathrm{BAB}$ (hereafter abridged as oxidant) have been investigated at several initial concentrations of the reactants, under pseudo first-order conditions of [oxidant]。 > [substrate $]_{0}$, in presence of $\mathrm{HClO}_{4}$ at $298 \mathrm{~K}$ in both cases. The kinetic and mechanistic features for the oxidation of FRE with the closely related compounds $\mathrm{CAB}$ and $\mathrm{BAB}$ in $\mathrm{HClO}_{4}$ medium are same under identical experimental conditions but the comparative rates of oxidation of FRE by BAB are about three-fold faster than $\mathrm{CAB}$.

Under the conditions [oxidant $]_{0}>>[\mathrm{FRE}]_{0}$ at constant $[\text { oxidant }]_{0},\left[\mathrm{HClO}_{4}\right]$, temperature, plots of log (absorbance) versus time were linear ( $r>0.9952)$ indicating a first-order dependence of rate on $[\mathrm{FRE}]_{0}$ in both the cases. The linearity of these plots in both cases, together with the constancy of the slopes obtained at different $[\mathrm{FRE}]_{0}$, substantiates the first-order dependence of rate on $[\mathrm{FRE}]_{0}$. The pseudo first-order rate constants $\left(\mathrm{k}^{\prime}\right)$ obtained are recorded in Table 1 . Under the same experimental conditions the rate of reaction increased in [oxidant] $]_{0}$ (Table 1 ) and plots of $\log \mathrm{k}^{\prime}$ versus $\log$ [oxidant] were linear ( $\left.\mathrm{r}>0.9955\right)$ with unit slopes in both the cases. This establishes that the order of the reaction is first-order with respect to [oxidant] $]_{0}$. Further, plots of $\mathrm{k}^{\prime}$ versus [oxidant] $]_{0}$ were linear $(\mathrm{r}>0.9980)$ passing through the origin corroborate the first-order dependence on [oxidant $]_{0}$.

The rate of reaction augmented with increase in $\left[\mathrm{HClO}_{4}\right]$ (Table 1) and plots of $\log k^{\prime}$ versus $\log$ $\left[\mathrm{HClO}_{4}\right]$ were linear $(r>0.982)$ with slopes of 0.69 and 0.66 for $\mathrm{CAB}$ and $\mathrm{BAB}$, showing a fractional-order dependence on $\left[\mathrm{HClO}_{4}\right]$.

\subsection{Effects of halide ions and benzenesulfonamide concentration on the rate}

Addition of halide ions, $\mathrm{Cl}^{-}$or $\mathrm{Br}^{-}$, in the form of their sodium salts $\left(1.0 \times 10^{-3}-8.0 \times 10^{-3} \mathrm{~mol} \mathrm{dm}^{-3}\right)$ showed no pronounced effect on the rate. This indicates that the halide ions play no role in the reaction. The ionic strength of the reaction medium was varied from 0.1 to $0.3 \mathrm{~mol} \mathrm{dm}^{-3}$ with $\mathrm{NaClO}_{4}$ solution keeping other experimental conditions constant. It was found that addition of $\mathrm{NaClO}_{4}$ showed negligible effect on the reaction rate, representing the participation of nonionic species in the rate-determining step. Hence no attempts were made to maintain the ionic strength of the medium stable for kinetic runs. Addition of benzenesulfonamide $\left(\mathrm{RNH}_{2}\right)$ to the reaction mixture $\left(5.0 \times 10^{-3} \mathrm{~mol} \mathrm{dm}^{-3}\right)$ did not influence the rate significantly indicates that $\mathrm{RNH}_{2}$ is not involved in any step prior to the rate determining step of the proposed scheme. 


\subsection{Effect of dielectric constant of the medium on the rate}

The dielectric constant (D) of the medium was mottled by adding $\mathrm{MeOH}(0-30 \% \mathrm{v} / \mathrm{v})$ to the reaction mixture with all other experimental conditions being held constant but the rates were not considerably altered with both the oxidants.

\subsection{Effect of solvent isotope on the rate}

Since the oxidation of FRE by $\mathrm{CAB}$ and $\mathrm{BAB}$ was increased with $\mathrm{H}^{+}$ions, the solvent isotope effect was studied in $\mathrm{D}_{2} \mathrm{O}$ as the solvent medium for both the oxidants. The rate constants for $\mathrm{CAB}$ and $\mathrm{BAB}$ revealed that $k^{\prime}\left(\mathrm{H}_{2} \mathrm{O}\right)$ was equal to $3.26 \times 10^{-4} \mathrm{~s}^{-1}$ and $9.80 \times 10^{-4} \mathrm{~s}^{-1}$, and $k^{\prime}\left(\mathrm{D}_{2} \mathrm{O}\right)$ was $3.75 \times 10^{-4} \mathrm{~s}^{-1}$ and $12.7 \times 10^{-4} \mathrm{~s}^{-1}$, respectively. Thus, the solvent isotope effect, $k^{\prime}\left(\mathrm{H}_{2} \mathrm{O}\right) / k^{\prime}\left(\mathrm{D}_{2} \mathrm{O}\right)$ were found to be 0.86 and 0.77 for $\mathrm{CAB}$ and $\mathrm{BAB}$.

\subsection{Effect of temperature on the rate}

The reaction was studied at different temperatures (288-313 K), keeping other experimental conditions constant. From Arrhenius plots of $\log k^{\prime}$ vs. $1 / \mathrm{T}(r>0.9955)$, composite activation parameters $\left(\mathrm{E}_{\mathrm{a}}, \Delta \mathrm{H}^{\ddagger}, \Delta \mathrm{S}^{\ddagger}\right.$, $\Delta \mathrm{G}^{\neq}$and $\log \mathrm{A}$ ) were computed for the oxidation of FRE by CAB and BAB. These data are summarized in Table 2 .

\subsection{Test for free radicals}

Alkene monomers such as acrylonitrile and freshly prepared $10 \%$ acrylamide solutions were added to the reaction mixture to instigate polymerization by free radicals formed in situ. The lack of polymerization indicated the absence of free radicals in the reaction mixture. This clearly ruled out the possibility of free radical mechanism. The controlled experiments were also performed under similar reaction conditions without oxidant.

\subsection{Reactive species of sodium N-halo-benzenesulfonamides}

Organic N-haloamines are sources of positive halogens and these reagents have been exploited as oxidant for a variety of substrates in both acidic and alkaline media $[12,16]$. Since organic N-haloamines have analogous chemical properties, it is predicted that identical equilibria exist in aqueous acidic and basic solutions of these compounds [25-26]. Chloramine-B and bromamine-B act as oxidizing agents in acidic and alkaline media [27-29] with a two electron change per mole giving benzenesulfonamide (BSA) and $\mathrm{NaCl}$ or $\mathrm{NaBr}$. The redox potential of CAT-PTS couple is $\mathrm{pH}$ dependent [25] and decreases with increase in $\mathrm{pH}$ of the medium $\left(\mathrm{E}_{\text {redox }} 1.138 \mathrm{~V}, 1.778 \mathrm{~V}, 0.614 \mathrm{~V}\right.$ and $0.5 \mathrm{~V}$ at pH $0.65,7.0,9.7$ and 12 , respectively). In view of the homogeneity in properties of $\mathrm{N}$-haloamines, similar redox potential behaviour can be expected for $\mathrm{CAB}$ and $\mathrm{BAB}$ also. The nature of the active oxidizing species and mechanism depends on the nature of halogen atom, the groups attached to the nitrogen and the reaction condition. The species accountable for such oxidizing character may be different depending on the $\mathrm{pH}$ of the medium.

Chloramine-B and bromamine-B (RNXNa) are moderately strong electrolytes [26] in aqueous solutions ( $\mathrm{RNXNa} \rightleftharpoons \mathrm{RNX}^{-}+\mathrm{Na}^{+}$), and depending on the $\mathrm{pH}$ of the medium, these reagents furnish different types of reactive species in solutions [26, 28-29]. The possible oxidizing species present in acid medium are RNHX, $\mathrm{RNX}_{2}, \mathrm{HOX}$ and also perhaps $\mathrm{H}_{2} \mathrm{OX}^{+}$.

\subsection{Reaction scheme}

In the present studies, the first-order dependence of rate on [oxidant $]_{0}$ and no effect of rate on $\left[\mathrm{RNH}_{2}\right]_{3}$ clearly ruled out the opportunity of both $\mathrm{RNX}_{2}$ and $\mathrm{HOX}$ as reactive species. The probability of the dichloro compound as the reactive species is ruled out, since clear first-order plots are obtained for the desertion of the [substrate]. Added benzenesulfonamide does not hinder the reaction indicating that HOX is not principally involved in the rate determining step. Further, Bishop and Jennings [28] have shown in their studies on aqueous solutions of CAT, that $\mathrm{pH} \sim 3-4$, the concentration of anion $\mathrm{TsN}^{-} \mathrm{Cl}$ is greater than that of the free acid.

$$
\mathrm{TsNCl}^{-}+\mathrm{H}^{+} \rightleftharpoons \mathrm{TsNHCl}
$$

Where Ts is $\mathrm{CH}_{3} \mathrm{C}_{6} \mathrm{H}_{4} \mathrm{SO}_{2}$. Hence a protonation equilibrium (1) suggesting the anion can be assumed as the reactive oxidizing species. Since organic haloamines have similar chemical properties, the same equilibrium can be expected for $\mathrm{CAB}$ and $\mathrm{BAB}$ also. 


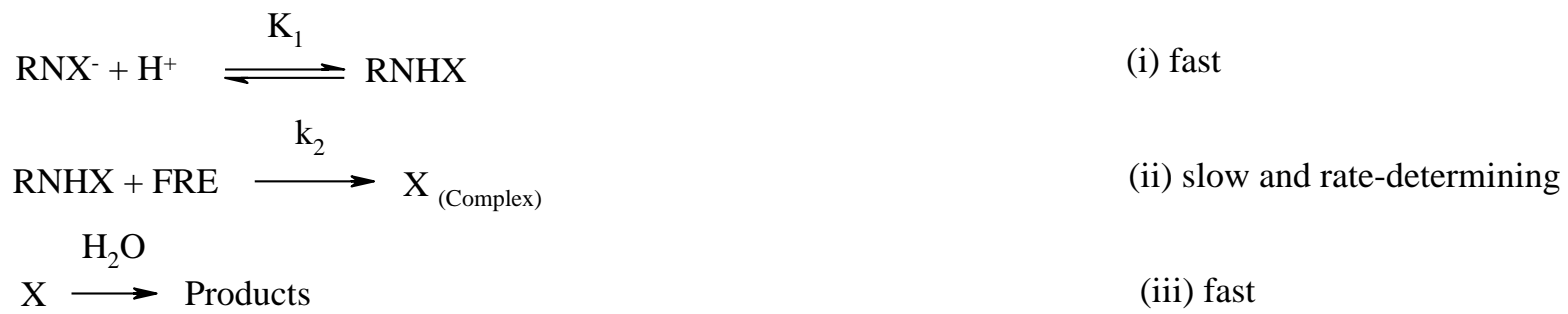

Scheme 2. A general reaction scheme for the oxidation of FRE by CAB and BAB in acid medium.

In general azo dyes containing hydroxyl groups conjugated to azo group exhibit azo-hydrazone tautomerism. Since FRE belongs this class of monoazo dyes and hence it exhibits tautomerism as shown below.<smiles>NS(=O)(=O)c1ccc2cc(O)c(N=Nc3ccc(S(N)(=O)=O)c4ccccc34)cc2c1</smiles>

(Azo)<smiles></smiles>

(Hydrazone)

In the present case, the azo form of the dye reacts with the conjugate acid of the oxidant to form a FREoxidant complex (X) with the elimination of $\mathrm{RNH}_{2}$. The complex in acid medium undergoes protodesulfonation followed by hydrolysis and cleavage of azo bond to yield the ultimate products naphthalein and 1,2naphthaquinone as shown in scheme 2 .

\subsection{Kinetic rate law}

A detailed mode of oxidation of FRE by CAB and BAB in acid medium is illustrated in Scheme 2, where the structure of the transitional complex $X$ is shown. In a fast initial equilibrium (step (i) of Scheme 1), the anion $\mathrm{RNX}^{-}$, in acid accelerating step generates the active oxidizing species RNHX. In a slow / rate limiting step (step (ii)), the lone pair of electrons on oxygen of FRE attacks the positive halogen of RNHX forming an intermediate species X. This intermediate complex X (step (iii)) undergoes hydrolysis followed by several fast steps leading to the formation of naphthaquinone and naphthalene as end products.

If [oxidant] $]_{\mathrm{t}}$ represents the total concentration of the oxidant, then from steps (i) and (ii) of Scheme 1,

$$
\text { [oxidant }]_{\mathrm{t}}=\left[\mathrm{RN}^{-} \mathrm{X}\right]+[\mathrm{RNHX}]
$$

By substituting [RN'X] from step (i) of Scheme 1, into Eqn 9 and solving for [RNHX], one gets,

$$
[\mathrm{RNHX}]=\frac{\left.\mathrm{K}_{1} \text { [oxidant }\right]_{\mathrm{t}}\left[\mathrm{H}^{+}\right]}{1+\mathrm{K}_{1}\left[\mathrm{H}^{+}\right]}
$$

From the slow and rate determining step (step (ii) of Scheme 1),

Rate $=\mathrm{k}_{2}[\mathrm{RNHX}][\mathrm{FRE}]$

By substituting for [RNHX] from Eqn 10 into Eqn 11, the following rate law is obtained:

$$
\text { Rate }=\frac{\left.\mathrm{K}_{1} \mathrm{k}_{2} \text { [oxidant }\right]_{\mathrm{t}}[\mathrm{FRE}]\left[\mathrm{H}^{+}\right]}{1+\mathrm{K}_{1}\left[\mathrm{H}^{+}\right]}
$$

The derived rate law 12 is in good agreement with the experimental results, wherein a first order dependence of rate on each [oxidant $]_{o}$ and $[\mathrm{FRE}]_{\mathrm{o}}$ and a fractional-order dependence on $\left[\mathrm{H}^{+}\right]$.

In the present investigations, disparity of dielectric constant of the medium does not have an effect on the rate appreciably. The effect of varying solvent composition and dielectric constant on the rate of reaction has been described in several studies [30-34]. For limiting case of zero angle of approach between two dipoles or an ion-dipole system, Amis [33] has shown that a plot of $\log \mathrm{k}^{\prime}$ versus $1 / \mathrm{D}$, gives a straight line with a negative 
slope for a reaction between a negative ion and a dipole or between two dipoles, where a positive slope results for a positive ion-dipole interaction. The total absence of the effect of varying dielectric constant on the rate cannot be explained by the Amis theory [33]. Applying the Born equation, Laidler [34] has anticipated the following equation for a dipole-dipole interaction:

$\ln \mathrm{k}^{\prime}=\ln \mathrm{k}_{\mathrm{o}}+3 / 8 \mathrm{kT}(2 / \mathrm{D}-1)\left[\mu_{\mathrm{A}}^{2} / \mathrm{r}_{\mathrm{A}}^{3}+\mu_{\mathrm{B}}^{2} / \mathrm{r}_{\mathrm{B}}^{3}-\mu_{\neq}^{2} / \mathrm{r}_{\neq}^{3}\right]$

where $\mathrm{k}_{\mathrm{o}}$ is the rate constant in a medium of infinite dielectric constant, $\mu$ represents the dipole moment and $\mathrm{r}$ refers to the radii of the reactants and activated complex. It can be seen from Eq. (13) that the rates should be greater in a medium of lower dielectric constant when $\mathrm{r}_{\neq}^{3}=\mathrm{r}_{\mathrm{A}}^{3}+\mathrm{r}_{\mathrm{B}}^{3}$ representing that the extent of charge scattering in the transition state is different. On the other hand, $\mathrm{r}_{\neq}{ }_{\neq} \approx \mathrm{r}_{\mathrm{A}}{ }^{3}+\mathrm{r}_{\mathrm{B}}^{3}$ implies the absence of a dielectric effect of the solvent on the rate, as was observed in the present investigations, signifying that the transition state is not very much different from the reactants with respect to the size and charge of the transition state and the reactants.

Reactions in aqueous medium that are susceptible to acid-base catalysis have been studied in heavy water $\left(\mathrm{D}_{2} \mathrm{O}\right)$ after equilibrium. Since the majority oxidation reactions of organic compounds involve the cleavage of $\mathrm{C}-\mathrm{H}$ bond, deuterium isotope effect on such reaction gives information regarding the nature of the rate determining step. In the present investigations, solvent isotope studies have shown that the rate of reaction is higher in $\mathrm{D}_{2} \mathrm{O}$ medium. For a reaction involving a fast equilibrium $\mathrm{H}^{+}$or $\mathrm{OH}^{-}$ion transfer, the rate increases in $\mathrm{D}_{2} \mathrm{O}$ medium since $\mathrm{D}_{3} \mathrm{O}^{+}$or $\mathrm{OD}^{-}$are a stronger acid and a stronger base respectively, than $\mathrm{H}_{3} \mathrm{O}^{+}$and $\mathrm{OH}^{-}$ions [35-36]. The observed solvent isotope effect of $k^{\prime}\left(\mathrm{H}_{2} \mathrm{O}\right)$ and $k^{\prime}\left(\mathrm{D}_{2} \mathrm{O}\right)<1$ is due to the greater acidity of $\mathrm{D}_{3} \mathrm{O}^{+}$ compared to $\mathrm{H}_{3} \mathrm{O}^{+}$. However, the magnitude of increase in rate in $\mathrm{D}_{2} \mathrm{O}$ is small (expected value is 2-3 times greater). This may be due to the fractional order dependence of rate on $\left[\mathrm{H}^{+}\right]$. Hence, this observation supports the planned mechanism.

\subsection{Relative reactivity of $C A B$ and $B A B$}

A comparison of the rates of reaction of $\mathrm{CAB}$ and $\mathrm{BAB}$ shows that the oxidation of FRE is about threefold faster in $\mathrm{BAB}$ compared to $\mathrm{CAB}$, under identical set of experimental conditions. This is endorsed by the relative magnitudes of activation energies (Table 2). This trend may be attributed to the difference in elctrophilicities of the halocations, $\mathrm{Cl}^{+}$and $\mathrm{Br}^{+}$ions, involved in the oxidation processes and, is also related to the ease with which these species are generated in reactions. In these oxidation reactions, the electronegativity values of $\mathrm{Br}^{+}$and $\mathrm{Cl}^{+}$play a vital role. Bromine has the elctronegativity of 2.7 , while chlorine has a higher value of 2.8. As the elcetronegativity increases the electropositive nature decreases. Since the halo cations are the reactive species in these oxidation reactions, the electropositive nature is in the order: $\mathrm{Br}>\mathrm{Cl}$. Therefore the reactivity of $\mathrm{BAB}$ is more compared to $\mathrm{CAB}$. This trend may also be due to the moderate difference in the van der Waals's radii of bromine and chlorine. A similar behaviour has been observed in the oxidation of several other substrates using $\mathrm{CAB}$ and $\mathrm{BAB}$. The facts furnished in the present research and the literature reports $[16,17,20,37-38]$ lead to conclude that $\mathrm{BAB}$ is a stronger oxidant compared to CAB.

The negligible influence of difference of ionic strength and addition of benzenesulfonamide and halide ions are in conformity with the proposed mechanism. The proposed mechanism is also supported by the judicious value of energy of activation and other thermodynamic parameters (Table 2). The fairly high positive values of $\Delta G^{f}$ and $\Delta H^{\neq}$indicate the transition state is highly solvated while the negative entropy of activation reflects the formation of a compact and ordered transition state. Further, the experimental observation illustrates that there is no effect of benzenesulfonamide, halide ions and ionic strength on the reaction rate which also substantiates the anticipated mechanism.

In the present redox system the optimum conditions for the controlled oxidation of FRE by $\mathrm{CAB}$ and $\mathrm{BAB}$ to naphthalene and 1,2-naphthaquinone in acid medium have been developed. Accordingly, this redox system can be scaled up to industrial operation. Furthermore, FRE is one of the chief components in the effluents of various industries and is environmentally hazardous and also carcinogenic compound. Hence, the present simple method developed can be adopted for treating the FRE dye present in industrial effluents to reduce toxicity caused by this dye. Also, this method offers several advantages including short reaction time, cost effective and moderately non-toxic reagents which make the reaction process simple.

\section{Conclusions}

The kinetics of oxidation of FRE by $\mathrm{CAB}$ and $\mathrm{BAB}$ in acid medium obeys the rate law - $\mathrm{d}$ [oxidant] / $\mathrm{dt}$ $=\mathrm{k}$ [oxidant $]_{\mathrm{o}}[\mathrm{AB}]_{\mathrm{o}}\left[\mathrm{H}^{+}\right]^{\mathrm{x}}$, where $\mathrm{x}=0.69$ and 0.66 for $\mathrm{CAB}$ and $\mathrm{BAB}$ respectively. Oxidation products were identified by GC-MS analysis. The present method developed for the oxidative decolorization of FRE with CAB and $\mathrm{BAB}$ is advantageous. Furthermore, the simple and well-designed method developed in the present research can be implemented for treating FRE present in industrial effluents to diminish the toxicity caused by this dye. 


\section{Acknowledgement}

The authors are thankful to The Principal and The Management, Don Bosco Institute of Technology for the facilities and support. Financial assistance from Visvesvaraya Technological University Research Grants, NO VTU/Aca./2012-13/A-9/760 is gratefully acknowledged.

\section{References}

[1]. Zollinger, H., Colour chemistry: Synthesis, properties and applications of organic dyes and pigments, New York, VCH, 1981.

[2]. Perkowski, J., Ledakowicz, S., Fibres Text East Eur. 10, 68 (2002)

[3]. Waters, B.D., Colour in Dyehouse Effluent, Cooper, P. Ed. Society of Dyers and Colourists, Bradford, 1995.

[4]. Pearce, C.I., Lloyd, J.R., Guthrie, J.T., Dyes Pigments 58, 179 (2003)

[5]. Umbuzeiro, G.D.A., Freeman, H.S., Warren, S.H., De Oliveira, D.P., Terao, Y., Watanabe, T., Claxton, L.D., Chemosphere 60, 55 (2005)

[6]. Oakes, J., Gratton, P., J. Chem. Soc. Perkin Trans 2, 2201 (1998) and references therein.

[7]. Abrahat, E.N., Dyes and their intermediates, London, UK Edward AQrnolds Ltd. 1977.

[8]. Ligrini, O., Oliveros, E., Braun, A., Chem Rev, 93, 671 (1993)

[9]. J.J. Roxon, A.J. Ryan, S.E. Wright, Food Cosmet Toxicol, 5, 367 (1967)

[10]. M.M. Campbell, G. Johnson, Chem. Rev. 78, 65 (1978)

[11]. A.R.V. Murthy, B.S. Rao, Proc Indian Acad. Sci. 35, 69 (1952)

[12]. K.K. Banerji, B. Jayaram, D.S. Mahadevappa, J. Sci. Ind. Res. 46, 65 (1987)

[13]. D.H. Brenner, In. Synth. Reagents 6, 9 (1985)

[14]. B.T. Gowda, D.S. Mahadevappa, J. Chem. Soc. Perkin Trans. II 323, (1983)

[15]. A. Geethanjali, Synlett. 18, 2857 (2005)

[16]. E. Kolvari, A. Ghorbani-Choghamarani, P. Salehi, F. Shirini, M.A. Zolfigol, J. Iran. Chem. Soc. 4, 126 (2007)

[17]. Puttaswamy. D.S. Mahadevappa, K.S. Rangappa, Bull. Chem. Soc. Japan 62, 3343 (1989)

[18]. S. Ananda, M.B. Jagadeesha, Puttaswamy. B.M. Venkatesha, T.K. Vinod, N.M.M. Gowda,. Int. J. Chem. Kinet. 32, 776 (2000)

[19]. V. Shashikala, K.S. Rangappa, J. Carbohyd. Chem.21, 219 (2002)

[20]. Puttaswamy. R.V. Jagadeesh, Appl. Catal. A: Gen. 292, 259 (2005)

[21]. SP. Meenakshisundaram, R. Markkandan, Indian J. Chem. 44A, 71 (2005)

[22]. Puttaswamy, J.P. Shubha, Bull. Korean Chem. Soc. 30 (9), 1939 (2009)

[23]. M.S. Ahmed, D.S. Mahadevappa, Talanta 27, 669 (1980)

[24]. J.C. Morris, J.A. Salazar, M.A. Wineman, J. Am. Chem. Soc. 70, 2036, (1948)

[25]. R.J.D. Saldanha, S. Ananda, B.M. Venkatesha, N.M.M. Gowda, J. Mol. Struct. 147, 606 (2002)

[26]. E. Bishop, V.J. Jennings, Talanta, 1,197 (1958)

[27]. K.S. Rangappa, H. Ramachandra, D.S. Mahadevappa, N.M.M. Gowda, Int. J. Chem. Kinet. 28, 265 (1996)

[28]. F.F. Hardy, J.P. Johnston J. Chem. Soc. Perkin Trans II 742, (1973)

[29]. B.G. Pryde, F.G. Soper, J. Chem. Soc. 1582, (1962)

[30]. E.A. Moelwyn-Hughes, The kinetics of reaction in solutions, Oxford, Clarender Press, 374, 1947.

[31]. A.A. Frost, R.G. Pearson, Kinetics and Mechanism, New York, Wiley 135, (1961)

[32]. E.S. Amis, Rates Anal. Chem. 27, 1672 (1955)

[33]. K.J. Laidler, Chemical kinetics New Delhi, Tata Mc Graw-Hill, 211,(1955)

[34]. C. Reichardt, Solvent and Solvent Effects in Organic Chemistry New York, Wiley- Vctt, 219, (2003)

[35]. C.J. Collins, N.S. Bowman, Isotope Effects in Chemical Reactions New York, Van- Nostrand, $267,1970$.

[36]. A. Kohen, H.H. Limbach, Isotope Effects in Chemistry and Biology. Florida, CRC Press, 827 (2006)

[37]. H.M.K. Naidu, B. Yamuna, D.S. Mahadevappa, Indian J. Chem. 26A, 114 (1987)

[38]. Puttaswamy, R.V. Jagadeesh, Int. J. Chem. Kinet.38, 48 (2006).

Table - 1 Effect of Variation of oxidant, FRE and $\mathrm{HClO}_{4}$ concentrations on the reaction rate at $298 \mathrm{~K}$

\begin{tabular}{|c|c|c|c|c|}
\hline $10^{3}$ [oxidant] & $10^{4}[\mathrm{FRE}]_{\mathrm{o}}$ & $10^{4}\left[\mathrm{HClO}_{4}\right]$ & \multicolumn{2}{|c|}{$10^{4} k^{\prime}\left(\mathrm{s}^{-1}\right)$} \\
\hline$\left(\mathrm{mol} \mathrm{dm}{ }^{-3}\right)$ & $\left(\mathrm{mol} \mathrm{dm}{ }^{-3}\right)$ & $\left(\mathrm{mol} \mathrm{dm}^{-3}\right)$ & $\mathrm{CAB}$ & $\overline{\mathrm{BAB}}$ \\
\hline 0.8 & 2.5 & 2.0 & 0.73 & 2.19 \\
\hline 1.6 & 2.5 & 2.0 & 1.68 & 5.01 \\
\hline 3.2 & 2.5 & 2.0 & 3.26 & 9.80 \\
\hline 4.0 & 2.5 & 2.0 & 4.23 & 12.7 \\
\hline 5.0 & 2.5 & 2.0 & 7.22 & 21.4 \\
\hline 3.2 & 1.0 & 2.0 & 3.36 & 9.84 \\
\hline 3.2 & 2.0 & 2.0 & 3.62 & 9.57 \\
\hline 3.2 & 2.5 & 2.0 & 3.26 & 9.80 \\
\hline 3.2 & 4.0 & 2.0 & 3.72 & 9.91 \\
\hline 3.2 & 5.0 & 2.0 & 3.02 & 9.69 \\
\hline 3.2 & 2.5 & 0.5 & 1.22 & 3.52 \\
\hline 3.2 & 2.5 & 1.0 & 2.34 & 7.05 \\
\hline 3.2 & 2.5 & 2.0 & 3.26 & 9.80 \\
\hline 3.2 & 2.5 & 3.0 & 4.60 & 13.6 \\
\hline 3.2 & 2.5 & 4.0 & 6.72 & 17.4 \\
\hline
\end{tabular}


Table - 2 Temperature dependence on the reaction rate and activation parameters for the oxidation of FRE by $\mathrm{CAB}$ and $\mathrm{BAB}$ in acid medium.

\begin{tabular}{clc}
\hline Temperature $(\mathrm{K})$ & $10^{4} k^{\prime}\left(\mathrm{s}^{-1}\right)$ & $10^{4} k^{\prime}\left(\mathrm{s}^{-1}\right)$ \\
\hline 283 & $\mathrm{CAB}$ & $\mathrm{BAB}$ \\
288 & 1.12 & 4.58 \\
298 & 1.40 & 5.95 \\
303 & 3.26 & 9.80 \\
313 & 4.87 & 12.2 \\
$\mathrm{E}_{\mathrm{a}}\left(\mathrm{kJ} \mathrm{mol}^{-1}\right)$ & 9.05 & 16.5 \\
$\Delta H^{\mp}\left(\mathrm{kJ} \mathrm{mol}^{-1}\right)$ & 50.7 & 30.9 \\
$\Delta G^{\ddagger}\left(\mathrm{kJ} \mathrm{mol}^{-1}\right)$ & 48.2 & 28.4 \\
$\Delta S^{\ddagger}\left(\mathrm{JK}^{-1} \mathrm{~mol}^{-1}\right)$ & 92.9 & 90.1 \\
& -150 & -207 \\
\hline
\end{tabular}

[oxidant $]_{\mathrm{o}}=2.0 \times 10^{-4} \mathrm{~mol} \mathrm{dm}^{-3} ;[\mathrm{FRE}]_{\mathrm{o}}=1.8 \times 10^{-3} \mathrm{~mol} \mathrm{dm}^{-3} ;\left[\mathrm{HClO}_{4}\right]=1.2 \times 10^{-4} \mathrm{~mol} \mathrm{dm}^{-3}$.

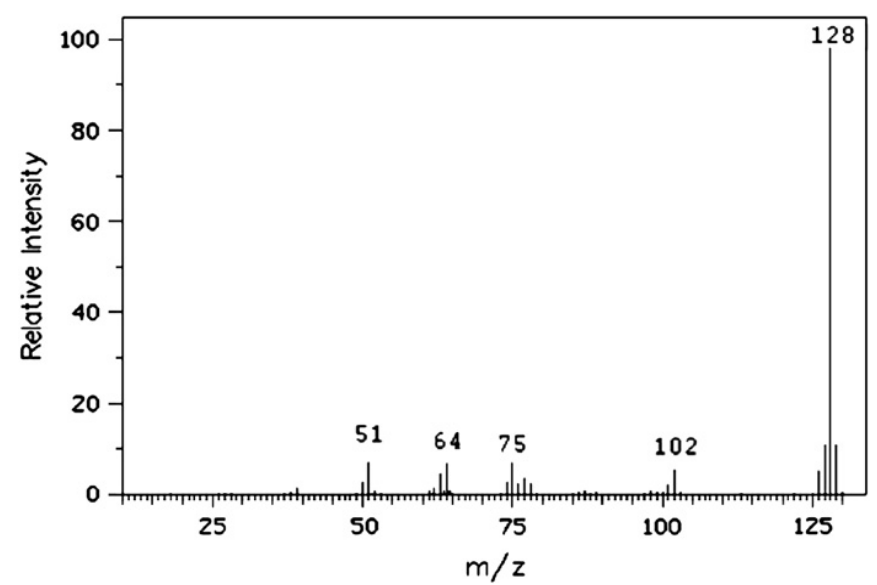

Fig- 1 GC-Mass spectrum of naphthalene with its molecular ion peak at128 amu.

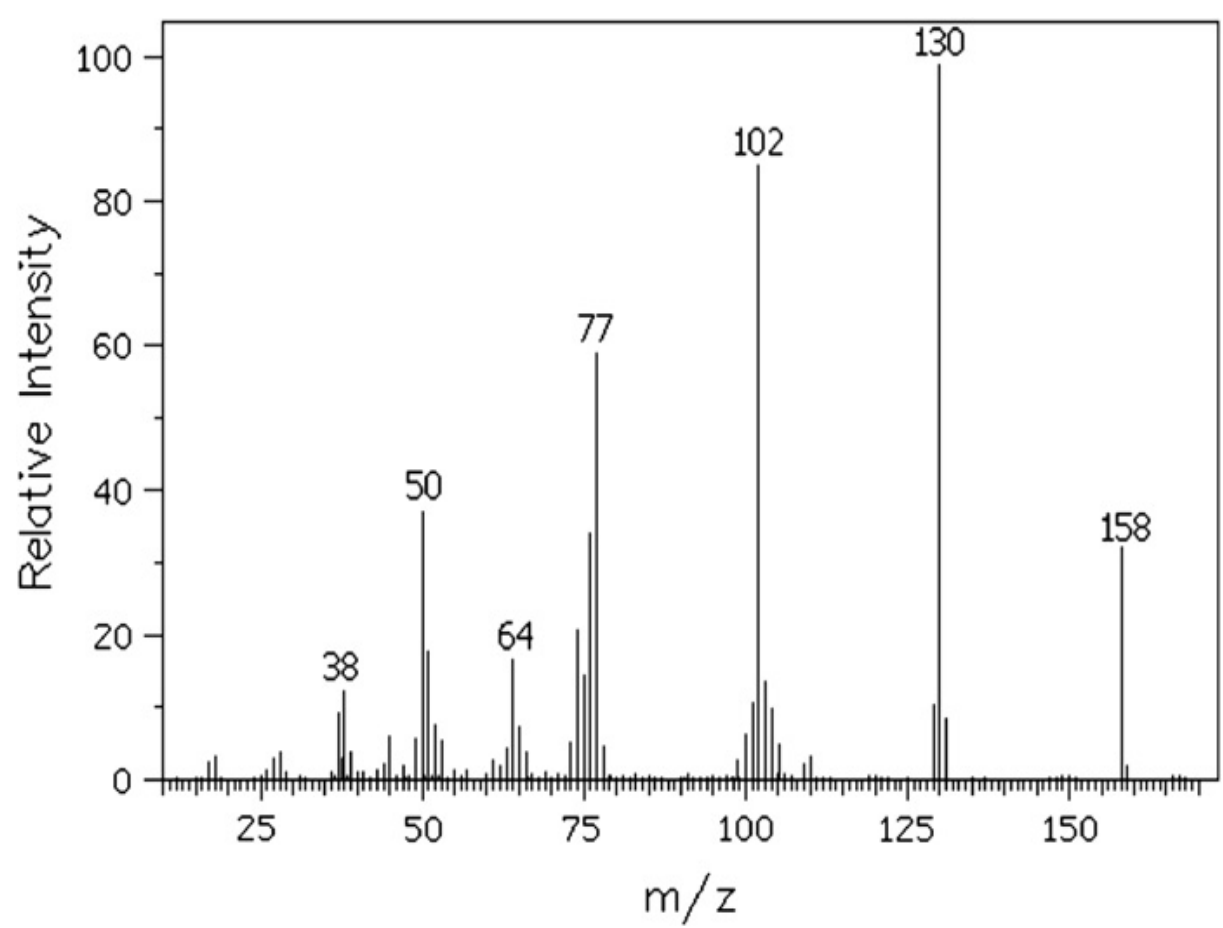

Fig- 2 GC-Mass spectrum of naphthaquinone with its molecular ion peak at158 amu. 


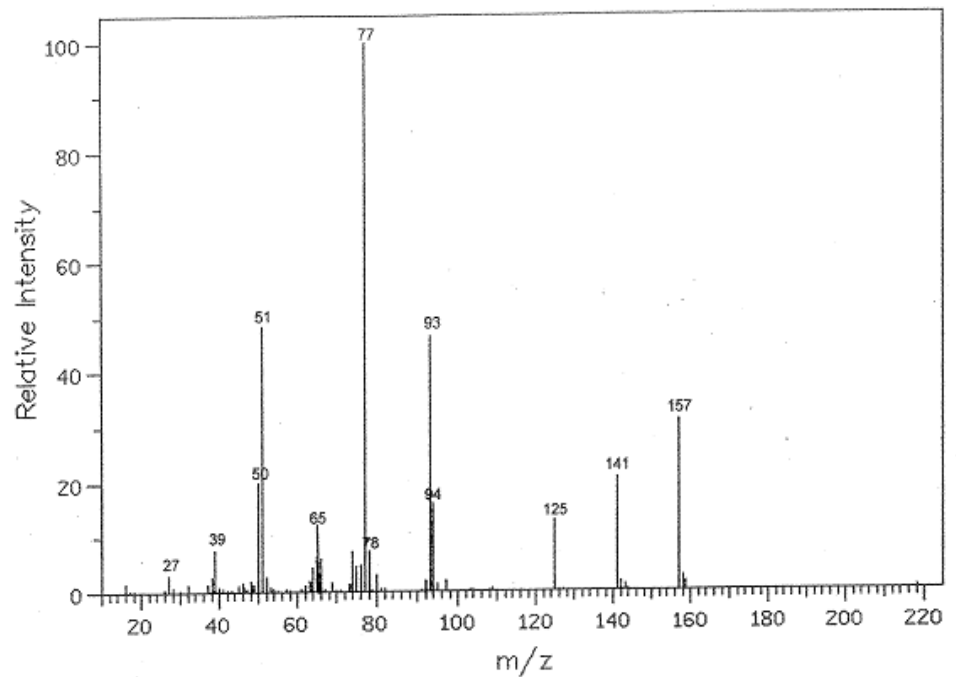

Fig - 3 GC-Mass spectrum of benzenesulfonamide with its molecular ion peak at $157 \mathrm{amu}$.

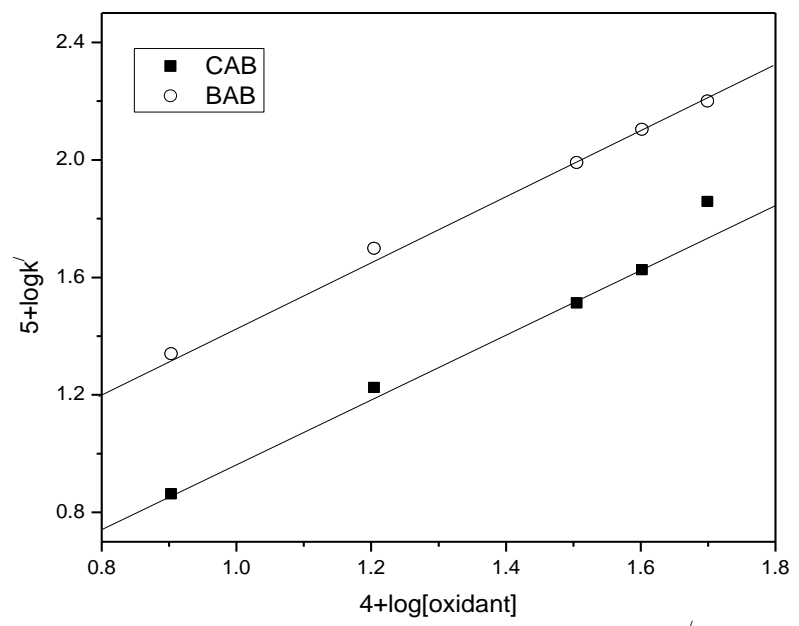

Fig. 4 Plot of $\log$ [oxidant] versus $\log \mathrm{k}^{\prime}$.

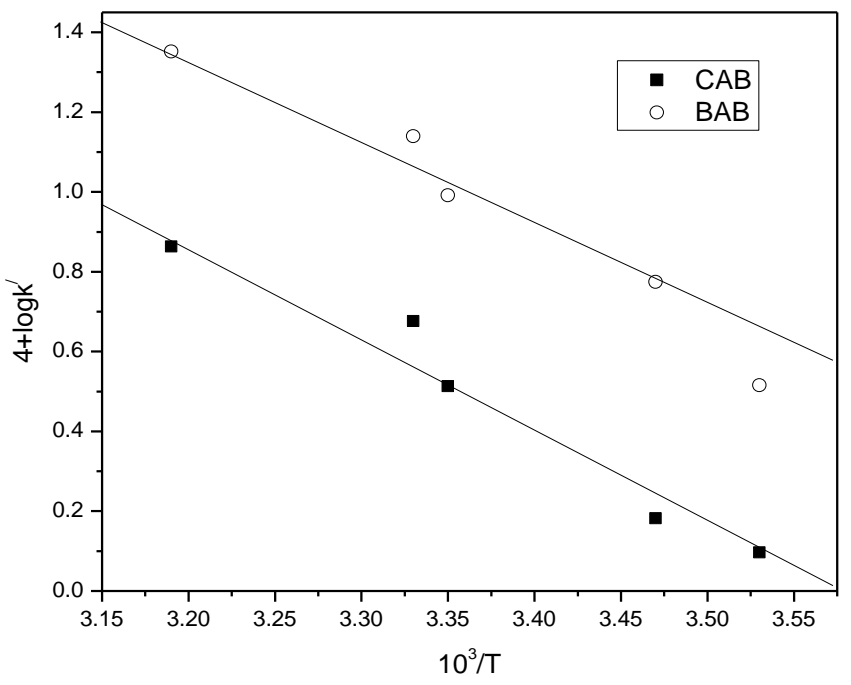

Fig. 5 Plot of $1 / \mathrm{T}$ versus $\log \mathrm{k}^{\prime}$. 
(i)
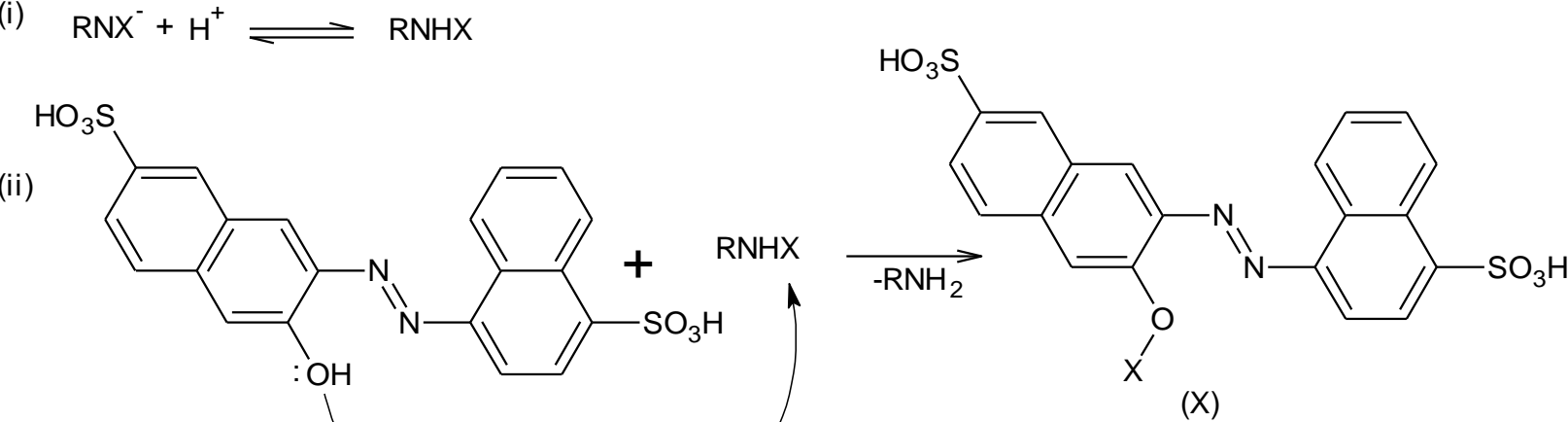

$(\mathrm{X})$ $\mathrm{HO}_{3} \mathrm{~S}$

iii)<smiles>[X]Oc1cc2ccc(S)cc2cc1/N=N/c1ccc(S(=O)(=O)O)c2ccccc12</smiles>

$(\mathrm{X})$

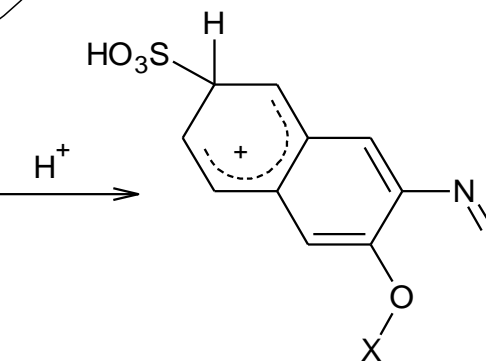<smiles>CNc1ccc(S(=O)(=O)O)c2ccccc12</smiles><smiles>[X]Oc1cc2ccccc2cc1N=N</smiles><smiles>[X]Oc1cc2ccccc2cc1/N=N/c1ccc(S(=O)(=O)O)c2ccccc12</smiles>

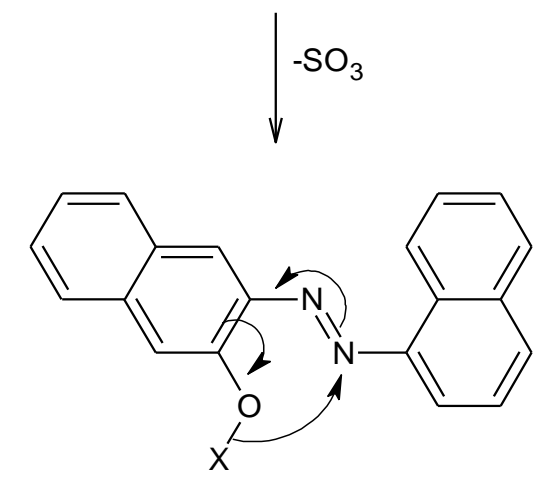<smiles>CCCCCC</smiles><smiles>[Y]N(/N=C1\C=c2ccccc2=CC1=O)c1cccc2ccccc12</smiles><smiles>c1ccc2ccccc2c1</smiles><smiles>c1ccc2c(N=NC3CCC3)cccc2c1</smiles><smiles>[R]C#CC1=CC(=O)C(=O)C=C1</smiles>

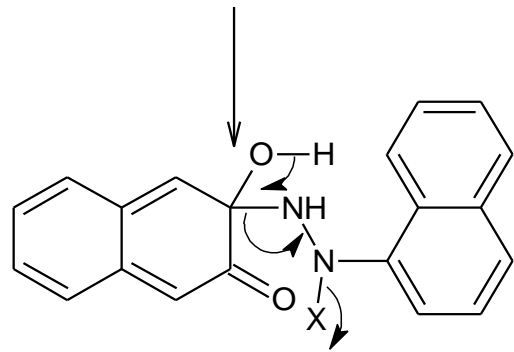

Scheme 3. Detailed mechanistic interpretation for the oxidation of FRE by CAB and BAB in acid medium. 